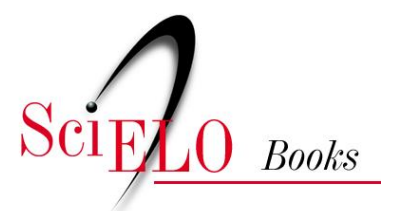

\title{
Antecedentes indígenas
}

\author{
Capistrano de Abreu
}

\section{SciELO Books / SciELO Livros / SciELO Libros}

ABREU, C. Antecedentes indígenas. In: Capítulos da história colonial [online]. Rio de Janeiro: Centro Edelstein de Pesquisa Social, 2009. pp. 1-11. ISBN: 978-85-7982-071-7.

https://doi.org/10.7476/9788579820717.0001.

\section{() pubulic}

This work is free of known copyright restrictions. http://creativecommons.org/publicdomain/mark/1.0/

Este trabalho está livre de restrições de direito de autor e/ou de direitos conexos conhecidas.

http://creativecommons.org/publicdomain/mark/1.0/

Esta obra está libre de restricciones conocidas de derechos autorales. http://creativecommons.org/publicdomain/mark/1.0/ 


\section{ANTECEDENTES INDÍGENAS}

A quase totalidade do Brasil demora no hemisfério meridional, e entre o Equador e o trópico de Capricórnio alcança o país as maiores dimensões.

Cercam-no ao Sul, a Sudoeste, Oeste e Noroeste as nações castelhanas do continente, exceto o Chile, por se interpor a Bolívia, e o Panamá por se interpor a Colômbia. Se confrontará algum dia com o Equador hão de decidir negociações ainda ilíquidas. Desde o alto rio Branco até beira-mar seguem-se colônias de Inglaterra, Holanda e França, ao Norte.

Banha-o ao Oriente o oceano Atlântico, numa extensão pouco mais ou menos de oito mil quilômetros. Como o cabo de Orange, limite com a Guiana Francesa, dista 37 graus do Chuí, limite com o Uruguai, salta logo aos olhos a insignificância da periferia marítima; repete-se o espetáculo observado na África e na Austrália: nem o mar invade, nem a terra avança; faltam mediterrâneos, penínsulas, golfos, ilhas consideráveis; os dois elementos coexistem quase sem transições e sem penetração; com recursos próprios o homem não pode ir além da pescaria em jangadas.

A borda litorânea dispõe-se em dois rumos principais: NoroesteSueste do Pará a Pernambuco, Nordeste-Sudoeste de Pernambuco ao extremo Sul.

A costa de NO-SE, corre baixa, quase retilínea, intermeada de dunas e lençóis de areia, aquém do Amazonas, baixa, lamacenta, de contornos variáveis, entre o Amazonas e o Oiapoque. Os materiais marinhos, os sedimentos fluviais dão-lhe o aspecto das costas compensadas; os portos rareiam, as barras dos rios são as verdadeiras entradas, em geral precárias. O desenvolvimento econômico ou as exigências administrativas mais que as condições naturais levam a navegação de longo curso para Belém, São Luís, Amarração, Fortaleza, Natal, Paraíba e Recife. Outros portos servem apenas à cabotagem. Tutoia franqueia o Parnaíba a embarcações de maior porte.

A costa de Sudoeste desde Pernambuco até Santa Catarina arrima-se à Serra do Mar, varia de aspecto, aqui extensões arenosas, além barreiras vermelhas, encostas cobertas de matas, ou montanhas que arcam com as 
ondas. Nela existem as maiores baías do Brasil: Todos os Santos, Camamu, Rio, Angra dos Reis, Paranaguá. A navegação de alto bordo procura as capitais dos estados, exceto as de Sergipe e Paraná, mais os portos de Santos, Paranaguá e S. Francisco do Sul. Também neste trecho se encontram as maiores e mais numerosas ilhas, em geral dentro de baías, todas de procedência continental.

A partir de Santa Catarina a costa se abaixa novamente; no Rio Grande do Sul dominam lagunas, cujo extenso litoral interno só poderá verdadeiramente prosperar quando a arte der a saída franca que a natureza lhes negou para o oceano.

As ilhas de procedência vulcânica, Fernão de Noronha, fronteira ao Rio Grande do Norte, Trindade, fronteira a Espírito Santo, pouco representam agora. Trindade parece imprópria à ocupação permanente: a Inglaterra só a disputou nos últimos anos por se prestar ao amarradio de cabos transatlânticos.

A faixa marítima apresenta largura variável: em geral avantaja-se mais de Pernambuco para o Pará, e no Rio Grande do Sul; no restante sua expansão subordina-se aos caprichos da serra do Mar: temos aqui as chamadas costas concordantes.

Ao Norte liga-se com a baixada do Amazonas, muito ampla à saída, relativamente estreita entre Xingu e Nhamundá, amplíssima a Oeste do Madeira e do Negro até o sopé dos Andes. As cachoeiras mais setentrionais do Tocantins, do Xingu, do Tapajós e do Madeira balizam a baixada pela banda do Sul. Pela banda do Norte, a Este do Negro, logo a algumas dezenas de quilômetros da foz, começa o trecho encachoeirado nos rios que descem da Guiana. De Este a Oeste apresenta declive insensível: mais desce o S. Francisco na cachoeira de Paulo Afonso do que o Amazonas nos três mil quilômetros que vão de Tabatinga ao mar.

A baixada marítima liga-se ainda ao Sul com a do Paraguai que começa no estatuário do Prata e prossegue até Mato Grosso. Cuiabá, na gema do continente, pouco mais de duzentos metros terá de altitude. As margens do rio principal, bastante altas no curso inferior, vão se abaixando à medida que se marcha para o Norte, até uma região anualmente alagada por espaços de muitas léguas, o chamado lago Xarais dos primeiros exploradores. Abundam aliás os lagos marginais, conhecidos pela denominação de baías; por uma série de baías passa a linha lindeira com a Bolívia.

As baixadas amazônica e paraguaia, contínuas com a do oceano, aproximam-se muito a Oeste: entre o Aguapeí, afluente do Jauru, tributário do Paraguai, e o Alegre, afluente do Guaporé, um dos formadores do Madeira, inserem-se apenas poucos quilômetros de distância. O governo português pensou em cortar este varadouro por um canal que levaria do Prata ao Amazonas, e deste, aproveitando o Cassiquiare, ao Orenoco, à ilha da Trinidad, ao mar das Antilhas.

A obra começada parou logo e parece inexequível, porque uma língua de terras bastante altas aparece e se estende até Chiquitos, na Bolívia, produzindo um desnivelamento pouco favorável.

As bacias do Amazonas e do Paraguai com os rios que as cortam, as ilhas numerosas, os lagos consideráveis e os canais sem conta compensam até certo ponto a pobreza do desenvolvimento marítimo, e são os verdadeiros mediterrâneos brasileiros. A depressão do Paraguai reunida à do alto Amazonas separa dos Andes as terras altas do Brasil, que a baixada amazônica ao Norte aparta do planalto da Guiana, e a baixada marítima precede pelos outros lados. A partir do Jauru, o Paraguai não recebe afluentes consideráveis em território brasileiro, à direita.

Desde o rio Uruguai o planalto brasileiro é limitado pela serra do Mar, áspera e coberta de matas na falda voltada para o oceano, mais suave na parte interior, de largura entre vinte e oitenta quilômetros, com picos que raramente passam de dois mil metros. Serve de divisora das águas entre os rios que procuram diretamente o Atlântico - em geral de pequeno curso, pois apenas dois, o Iguape e o Paraíba, rompem a serra, e os outros são rios transversais ou de meia água - e os rios que se destinam ao Prata, de muito maior extensão e cabedal: o Uruguai pertencente ao Brasil pelos dois lados até Peperi-guaçu, limite com a Argentina, e pelo lado esquerdo até Quaraím, limite com o Uruguai; o Iguaçu, com saltos de maravilhosa beleza, no trecho em que a esquerda pertence à Argentina e a direita ao Brasil; o Ivaí, próximo ao salto de Guairá; o Paranapanema, o Tietê, de tamanha significação histórica, e outros afluentes orientais do Paraná.

Da serra do Mar desprende-se a da Mantiqueira, que mais pelo interior vai desde o Estado do Paraná até Minas Gerais. Nela fica o pico 
mais alto do Brasil, o do Itatiaia, com cerca de três mil metros de altitude. Vem depois a serra do Espinhaço, que acompanha o rio S. Francisco pelo lado direito até ser cortada na grande curva traçada a Nordeste por ele antes de se lançar no oceano. Ambas representam papel somenos como divisoras das águas: a da Mantiqueira entre o Paraíba do Sul e o alto Paraná, a do Espinhaço entre o S. Francisco, de que estreita a bacia ao Oriente, logo depois de formado o rio das Velhas, e os rios de meia-água que se dirigem ao mar: Doce, Jequitinhonha, Pardo, Contas, Paraguaçu.

Das alturas de Barbacena arranca uma lombada transversal no rumo aproximado Este-Oeste que, com várias denominações, a trechos rigorosamente montanhosos, alhures meramente denudada, é o maior divisor das águas dentro do planalto. Chamou-a Serra das Vertentes o benemérito Eschwege, denominação excelente se, deixada de parte a estrutura, se atender somente ao papel representado na América do Sul. A um lado as águas vertem para o Paraná e para o Paraguai, ambos nascidos nesta zona e, como o Uruguai, terminando o curso em território estrangeiro; ao outro lado da vertente, correm os tributários do Madeira, objeto de longas disputas desde que Manuel Félix de Lima, em 1742, foi pela primeira vez das minas de Mato Grosso até a sua foz; o Tapajós, antigo caminho dos Cuiabanos para a compra do guaraná entre os Maués; o Xingu, cujas más condições de navegabilidade desviaram as explorações por muito tempo e deixaram viver até poucos anos numerosas tribos indígenas em pura idade da pedra, cujo estudo impulsionou poderosamente a etnografia sul-americana; o Araguaia-Tocantins, o Parnaíba, o S. Francisco.

O S. Francisco, de grande importância histórica, é formado pelo rio que com este nome desce da serra da Canastra, e pelo rio das Velhas. No trecho superior, os afluentes mais consideráveis correm entre estas duas cabeceiras até sua confluência; transposto já o salto de Pirapora, a divisora das águas com o Tocantins afasta-se e deixa que se desenvolvam o Paracatu, o Urucuia, o Carinhanha, o Corrente, o Grande, ao passo que a serra do Espinhaço se aproxima. Desde a barra do rio Grande para o mar, nem de uma, nem de outra margem concorre afluente algum considerável; os embaraços encontrados pela navegação acumulam-se, e tolheram as comunicações até ser transposto por uma via-férrea o trecho encachoeirado.

O S. Francisco é, por assim dizer, a imagem de quase todos os rios do Brasil: no planalto, apenas o volume de água o permite uma extensão de centenas de léguas, às vezes, perenemente navegável por embarcações de maior ou menor capacidade; em seguida, a descida do planalto com saltos e corredeiras, como os do Madeira, o Augusto no Tapajós, o Itaboca no Tocantins, o Paulo Afonso no S. Francisco, e tantos outros; finalmente, as águas se acalmam e aprofundam, e os embaraços de todo desaparecem quando lhes sobra força suficiente para impedir a formação de baixios na barra.

Deste tipo se apartam o Amazonas, cuja região tormentosa é vencida logo nas cabeceiras, muito antes de entrar no Brasil, e seus afluentes situados a Oeste do Madeira e do Negro, no chamado Solimões, nascidos todos em regiões pouco elevadas e logo difundidos por grandes baixadas, quase niveladas. Em menores dimensões reproduz-se o fato com o rio Paraguai e alguns de seus afluentes. O Parnaíba e os rios do Maranhão, descendo suavemente por um declive graduado ao longo do seu curso, apresentam uma forma de transição entre o tipo dos rios das baixadas e dos chapadões.

As montanhas preparam e os rios esculpem no planalto brasileiro quatro divisões bem distintas: o chapadão amazônico desde o Guaporé ao Tocantins; o do Parnaíba, inserido entre o primeiro e o do S. Francisco, mais vasto, que alcança sua maior expansão à margem esquerda desta bacia; finalmente o do Paraná-Uruguai, entre a serra do Mar e as montanhas de Guaiás. As relações existentes entre estes chapadões atuaram sobre o povoamento do território.

O planalto das Guianas apresenta outro chapadão elevado, com alguns picos graníticos, poucos de mais de mil metros.

A Oeste alguns afluentes amazônicos nascidos fora do Brasil, o Içá, Japurá, Negro, em seu trecho inferior correm por algum espaço paralelamente ao rio principal. Pouco extensas, pouco navegáveis correntes de meia-água desembocam a Este do Negro, descendo da borda meridional do chapadão das Guianas.

O rio das Amazonas vaza uma bacia de sete milhões de quilômetros quadrados, a maior do globo, tamanha, quase, como o Brasil inteiro. Sangram para ela grandes partes dos planaltos brasileiro, guianês e andino; como a quadra das chuvas não cai em todos eles ao mesmo tempo, sucede que quando começam a baixar os afluentes de um enchem os do outro lado, 
e a vazante nunca se dá completa. Às vezes tanto se avoluma o rio-mar que represa os tributários e por seus furos manda-lhes água a muitos quilômetros da foz. Os lagos marginais, as ilhas numerosas, os furos, os paranamirins permitiram navegar desde o oceano até os confins do país sem nunca penetrar na madre. Suas inundações alcançam quase vinte metros acima do nível ordinário; por cima das florestas podem então passar embarcações, das quais algumas semanas antes mal se avistava o topo do arvoredo. O Amazonas corre de Oeste para Este, acompanhando a equinocial, e seu clima pode dizer-se proximamente o mesmo em toda esta extensão: genuinamente tropical, pouco variável, sem diferenças sensíveis de temperatura, de atmosfera úmida, abundantemente chuvosa, máxime junto do mar e perto dos Andes. A maior ou menor frequência relativa de chuvas se designa pelos nomes de verão e inverno; de inverno só pode dar ideia aproximada, pelo lado da temperatura, o ligeiro refrigério sentido à noite.

Ao Sul do Amazonas, entre os rios Parnaíba e São Francisco, estende-se uma zona periodicamente flagelada por secas. Quando as estações correm regularmente há leves chuveiros, chamados de caju, à passagem do sol para o Sul; chuvas maiores caem antes ou depois do equinócio de março; São João é já fins d'água. No caso contrário secam os rios, exceto em alguns poços e depressões, murcham os pastos, permanecem nuas as árvores, sucumbe o gado à sede ou à inanição, e a gente morre à fome quando só dispõe dos recursos locais. A necessidade de lutar contra a calamidade inspirou a construção de açudes, a cultura das vazantes, a retirada do gado, a distribuição de ramas para alimentá-lo, as grandes levas de retirantes.

À beira-mar entre o Oiapoque e o Parnaíba, e do S. Francisco para o Sul domina igualmente o clima tropical até Santa Catarina: em alguns trechos quase todos os meses do ano chove, em outros intervêm estiadas maiores, em geral subordinadas à marcha solar.

A distância do equador avulta as diferenças termométricas, aliás contidas em extremos pouco apartados. Com o solstício de junho, pouco antes ou pouco depois, coincidem o maior abaixamento termométrico e a diminuição nos precipitados atmosféricos.
No Rio Grande do Sul as estações fria e quente já aparecem melhor delimitadas, as variações de temperatura tornam-se mais notáveis, e a estação das águas tende a emparelhar-se com a do frio.

Isto se refere ao litoral. No interior do país, reina também o clima tropical, modificado mais ou menos por fatores locais e revestindo certa feição continental. Geralmente chove no sertão menos que à beira-mar; as estações seca e úmida andam mais nitidamente discriminadas; o ar do planalto, facilmente aquecível durante o dia em consequência de sua pouca densidade, rapidamente esfria à noite pelo mesmo motivo, produzindo às vezes variações bruscas no decurso de vinte e quatro horas.

Também aqui as chuvas compassam-se pelo sol: em vários pontos há uma estação úmida menor e anterior, outra maior e posterior ao solstício de dezembro. Na depressão amazônica associam-se o calor e a umidade, a vegetação atinge o máximo desenvolvimento, alardeia-se grande mata terreal.

A luta pelo ar e pela luz arremessa as plantas para cima, repelem-se nas alturas as copas do arvoredo, árvores possantes viram trepadeiras, cruzam-se lianas em todos os sentidos. Plantas sociais como a imbaúba e a monguba constituem exceção; em regra numa superfície dada cresce o maior número possível de espécies diferentes.

Pouco influi sobre a fisionomia do conjunto a distância do oceano; muito mais atua o apartamento do rio: no caa-igapó, sujeito à inundação ânua, avultam palmeiras, muitas delas espinhosas, reduz-se o porte das árvores; no caa-eté, sobranceiro a ela, culminam gigantes vegetais triunfam dicotiledôneas e epífitos; mais adiante começam os xerófitos.

A região flagelada pela seca possui também matas, porém solteiras, nas serras capazes de condensarem vapores atmosféricos, nas margens dos rios, em lugares favorecidos pela umidade do subsolo. De dimensões restritas, sustentam a outros respeitos o confronto com as das regiões mais felizes; não representam, entretanto, fielmente a feição dominante.

Desde a Bahia começa a mata virgem contínua, e com os mesmos caracteres orla a borda oriental da serra do Mar: troncos eretos, ramificação muita acima do solo, folhagem sempre verdejante, variedade de espécies dentro de pequenas áreas, abundância de epífitos. Os acidentes topográficos 
introduzem aqui na paisagem uma variedade golpeante, desconhecida na monotonia intérmina da Amazônia.

Além da serra do Mar abrem-se os campos, vastas extensões ocupadas por gramíneas e ervas mais ou menos rasteiras.

Onde a altitude o permite surgem araucárias; em certos pontos adensam-se capões, cujo nome indígena está indicando a forma circular. Os campos do Sul explicam alguns pela baixa temperatura durante o período germinativo. Ao Norte existem igualmente campos, cuja explicação parece outra: o solo, muito quente e pouco úmido, requeimando as sementes das árvores, rouba-lhes a vitalidade.

Catinga, carrasco, cerrado, agreste designam todos várias formas de vegetação xerófila, caracterizada pelas raízes às vezes muito profundas, munidas muitas de bulbo que prende a água, pelo tronco áspero, gretado, exíguo, esgalhado, como se procurasse para os lados o desenvolvimento que lhe foge na vertical, pelas folhas mais ou menos miúdas, que caem numa parte do ano para melhor resistir à seca, limitando a evaporação.

Na região das secas esta forma de vegetação chega quase à beiramar; em quase todos os estados existe, mais ou menos, testemunho e efeito do clima continental. O povo brasileiro, começando pelo Oriente a ocupação do território, concentrou-se principalmente na zona da mata, que lhe fornecia pau-brasil, madeira de construção, terrenos próprios para cana, para fumo, e, afinal, para café. A mata amazônica forneceu também o cravo, o cacau, a salsaparrilha, a castanha e, mais importante que todos os outros produtos florestais, a borracha. Os campos do Sul produzem mate. Nos do Norte, em geral, e nas zonas de vegetação xerófila, plantam-se cereais ou algodão e pasta o gado. A obra do homem chama-se capoeira: terreno privado da vegetação primitiva, ocupado depois por vegetais adventícios cuja fisionomia ainda não assumiu feição bem caracterizada. Os capoeirões podem dar a ilusão de verdadeiras matas.

A fauna do Brasil é muita rica em insetos, reptis, aves, peixes, e pequenos quadrúpedes. São formas características as emas, os papagaios, os beija-flores, os desdentados, os marsúpios, os macacos platirrínios.

Na baixada litorânea, muitas formas de moluscos, peixes e aves há comuns ao Atlântico do Sul; o colorido de alguns por tal modo se assemelha à areia que custa descobri-los em repouso.
A fauna da mata apresenta, ao contrário, o colorido mais vistoso, principalmente nas borboletas, que às vezes atingem tamanho enorme, e nas aves. A maior parte das espécies adaptou-se à vida arbórea, e algumas, como a arcaica preguiça, vão desaparecendo com as derrubadas.

"Mais pálida em colorido e fraca em força numérica é a fauna do sertão" lembra Goeldi. Suntuoso uniforme de gala nos descampados não seria desejável nem proveitoso. Para os animais sertanejos é demais vantagem a sua roupa branco-amarelada e monótona que no meio do capim se conserva neutra entre a cor do solo e o colorido da macega torrada pelo sol.

Se por um lado, no litoral, é aparelho útil a asa comprida, apropriada ao voo persistente, e, por outro lado, o pé trepador, para o morador da mata, torna-se precioso dote para formas animais que vivem correndo pelo solo uma perna comprida e capaz de corresponder a fortes exigências. Aí estão para atestá-lo a seriema de alto coturno e a gigantesca ema. O próprio lobo brasileiro muniu-se, além de umas orelhas grandes, a modo de chacal do deserto, de longas pernas a feitio de galgo.

Entre estes animais nem um pareceu próprio ao indígena para colaborar na evolução social, dando leite, fornecendo vestimenta ou auxiliando o transporte; apenas domesticou um ou outro, os mimbabas da língua geral, - em maioria aves, principalmente papagaios, só para recreio. De caça e principalmente de pesca era composta sua alimentação animal. Possuía agricultura incipiente, de mandioca, de milho, de várias frutas. Como eram-lhe desconhecidos os metais, o fogo, produzido pelo atrito, fazia quase todos os ofícios do ferro. A plantação e colheita, a cozinha, a louça, as bebidas fermentadas competiam às mulheres; encarregavam-se os homens das derrubadas, das pescarias, das caçadas e da guerra.

As guerras ferviam contínuas; a cunhã prisioneira agregava-se à tribo vitoriosa, pois vigorava a ideia da nulidade da fêmea na procriação, exatamente com a da terra no processo vegetativo; os homens eram comidos em muitas tribos no meio de festas rituais. A antropofagia não despertava repugnância e parece ter sido muito vulgarizada: algumas tribos comiam os inimigos, outras os parentes e amigos, eis a diferença.

Viviam em pequenas comunidades. Pouco trabalho dava fincar uns paus e estender folhas por cima, carregar algumas cabaças e panelas; por 
isso andavam em contínuas mudanças, já necessitadas pela escassez dos animais próprios à alimentação.

De rixas minúsculas surgiam separações definitivas; grassava uma fissiparidade constante. Tradição muito vulgarizada explicava grandes migrações por disputas a propósito de um papagaio.

O chefe apenas possuía autoridade nominal. Maior força cabia ao poder espiritual. Acreditavam em seres luminosos, bons e inertes, que não exigiam culto, e poderes tenebrosos, maus, vingativos, que cumpria propiciar para apartar sua cólera e angariar-lhes o favor contra os perigos: eram as almas dos avós. Entre eles contava-se o curador, pagé ou caraíba, senhor da vida e da morte, que ressuscitara depois de finado, e não podia mais tornar a morrer.

Tinham os sentidos mais apurados, e intensidade de observação da natureza inconcebível para o homem civilizado. Não lhes faltava talento artístico, revelado em produtos cerâmicos, trançados, pinturas de cuia, máscaras, adornos, danças e músicas.

Das suas lendas, que às vezes os conservavam noites inteiras acordados e atentos, muito pouco sabemos: um dos primeiros cuidados dos missionários consistia e consiste ainda em apagá-las e substituí-las.

Falavam línguas diversas, quanto ao léxico, mas obedecendo ao mesmo tipo: o nome substantivo tinha passado e futuro como o verbo; o verbo intransitivo fazia de verdadeiro substantivo; o verbo transitivo pedia dois pronomes, um agente e outro paciente: a primeira pessoa do plura apresentava às vezes uma flexão inclusiva e outra exclusiva; no falar comum a parataxe dominava. A abundância e flexibilidade dos supinos facilitaram a tradução de certas ideias europeias.

Fundada no exame linguístico a etnografia moderna conseguiu agregar em grupos certas tribos mais ou menos estreitamente conexas entre si. No primeiro entram os que falavam a língua geral, assim chamada por sua área de distribuição. Predominavam próximo de beira-mar, vindos do sertão, e formavam três migrações diversas: a dos Carijós ou Guaranis, desde Cananeia e Paranapanema para o Sul e Oeste; os Tupiniquins, no Tietê, no Jequitinhonha, na costa e sertão da Bahia, na serra da Ibiapaba; os Tupinambás no Rio de Janeiro, a um e outro lado baixo S. Francisco até o
Rio Grande do Norte, e do Maranhão até o Pará. O centro de irradiação das três migrações deve procurar-se entre o rio Paraná e o Paraguai.

Nos outros grupos falavam-se as línguas travadas: os Gés, representados pelos Aimorés ou Botocudos próximo do mar, e ainda hoje numerosos no interior; os cariris disseminados do Paraguaçu até Itapecuru e talvez Mearim, em geral pelo sertão, conquanto os Tremembés habitassem as praias do Ceará; os Caraíbas, cujos representantes mais orientais são os Pimenteiras, no Piauí, ainda hoje encontrados no chapadão e na bacia do Amazonas; os Maipure ou Nu-Aruaque, que desde a Guiana penetraram até o rio Paraguai e ainda aparecem nas cercanias de sua antiga pátria, e até no alto Purus; os Panos, os Guaicurus, etc., etc.

Se abstrairmos do Amazonas, onde havia muitos Maipure e não poucos Caraíbas, só os Tupis e os Cariris foram incorporados em grande proporção à atual população do Brasil.

Os Cariris, pelo menos na Bahia e na antiga capitania de Pernambuco, já ocupavam a beira-mar quando chegaram os portadores da língua geral. Repelidos por estes para o interior, resistiram bravamente à invasão dos colonos europeus, mas os missionários conseguiram aldear muitos e a criação de gado ajudou a conciliar outros. Talvez provenha dos Cariris a cabeça chata, comum nos sertanejos de certas zonas.

Se agora examinarmos a influência do meio sobre estes povos naturais, não se afigura a indolência o seu principal característico. Indolente o indígena era sem dúvida, mas também capaz de grandes esforços, podia dar e deu muito de si. O principal efeito dos fatores antropogeográficos foi dispensar a cooperação.

Que medidas conjuntas e preventivas se podem tomar contra o calor? Qual o incentivo para condensar as associações? Como progredir com a comunidade reduzida a meia dúzia de famílias?

A mesma ausência de cooperação, a mesma incapacidade de ação incorporada e inteligente, limitada apenas pela divisão do trabalho e suas consequências, parece terem os indígenas legado aos seus sucessores. 